\title{
OPTIMIZATION OF SINGLY REINFORCED BEAM DESIGN USING SIMULATED ANNEALING
}

\author{
SIMON OLAYIWOLA ADEREMI OLAWALE ${ }^{1}$, OLUTOSIN PETER \\ AKINTUNDE*1, MOSES OLADIPUPO AFOLABI ${ }^{1}$, OLUWOLE AKINYELE \\ AGBEDE $^{1}$, OLUSOLA OLAYEMI FADIPE ${ }^{2}$
}

${ }^{1}$ Civil and Environmental Engineering Department, Bells University of Technology, $\mathrm{km} 8$, Idiroko, Benja Village, P.M.B. 1015, Ota, Ogun State, Nigeria

${ }^{2}$ Civil Engineering Department, Osun State University, Osogbo, Osun State, Nigeria

\begin{abstract}
This paper investigated the optimization of a singly reinforced concrete beam using the simulated annealing. The enhancement of minimum cost of structures and the adoption of the algorithm method of simulated annealing were projected in resolving the complications of constraints associated with optimization problems. The variables are the width, depth, compression steel, tension steel, and cost. The constraints are steel ratios, ultimate moment of resistance, maximum and minimum area of reinforcements while materials costs are considered as the objective function. It is demonstrated that using the concrete compressive strength of $25 \mathrm{MPa}$, simulated annealing can be used to optimize the design of concrete beams effectively. The results also indicate that the complications connected to the actual and genuine evaluation of costs of structures and the connectivity with the compulsory restraints can be adequately resolved using this method.
\end{abstract}

Keywords: beams, singly reinforced, optimum design, reinforced concrete, simulated annealing

\section{INTRODUCTION}

The design economy of R.C. structures is a result of the optimization concept. Experience, engineering judgment, intuition, and ability to design structures based on serviceability, safety, and economy are paramount. All of the above may not be fulfilled using the design codes. Hence, several iterative design procedures have to be engaged to arrive at the optimum solution.

This approach can result in generating a suitable preliminary outcome which can limit the repetitiveness of the design optimization. In recent times, the cost optimization of reinforced concrete beams design is fast becoming more popular due to the findings of many authors. Algorithms related to the singly reinforced concrete beams design and one-way slabs have been presented by many types of research among whom were Friel, Traum, Balagura, and Brown. Lagrangian multiplier technique was used by Balaguru to estimate the optimal amount of steel and dimensions for a rectangular beam in 1980.

Linearization techniques were used by AL-Nassiry in 2001 to resolve the problem of nonlinear optimization of reinforced rectangular beams. Structural works such as pre-stressed concrete beams have been optimized [1] so also force limiting anchorage systems [2]. A particle swarm optimization algorithm emerged in the late 1900s.

\footnotetext{
*Corresponding author, email: akintt18@gmail.com
}

(c) 2021 Alma Mater Publishing House 
This algorithm type was adopted by Van der Pol-Duffing in the recognition of oscillators [3] and [4]. Structural optimization can be branded using diverse methods.

The major objective is to produce a structure with optimal cost and weight reduction. The three basic materials used in structural construction are: reinforcement, concrete, and formwork [5]. Structural retrofitting is a suitable instance where optimized structure design can be founded on cost in addition to weight. [6] and [7] researched seismic loads reinforced concrete structures optimization. Special research attention should be paid to the concept of vibration reduction and enhancing the dynamics of R.C. structures using algorithm techniques.

Passive control systems of structures were optimized using a genetic algorithm [8] and [9] carried out the R.C cable-stayed bridge optimization under seismic effect. Three major components characterize optimization and these are: Optimized functions also called the objective function $(\mathrm{s}) \mathrm{f}_{1}(\mathrm{x}), \mathrm{f}_{2}(\mathrm{x}), \ldots, \mathrm{f}_{\mathrm{m}}(\mathrm{x})$; Independent variables also called the chromosomes $\mathrm{x}_{1}, \mathrm{x}_{2}, \ldots, \mathrm{x}_{\mathrm{n}}$, and Optimization Constraints; $\mathrm{g}_{1}(\mathrm{x}) \leq 0, \mathrm{~g}_{2}(\mathrm{x}) \leq 0, \mathrm{~g}_{\mathrm{n}}(\mathrm{x}) \leq 0$.

Hence, optimization means to determine independent variable(s) $\mathrm{x}$, optimize function(s) $\mathrm{f}$ in a manner to fulfil the constraint(s) $\mathrm{g}=\leq 0$.

Classical optimization methods were adopted before Meta heuristics optimization techniques surfaced. It was originated from the process of calculus starting from connecting the derivatives to zero, non-linear based programming, dynamic programming, up till integer-based programming, etc. These methods are characterized by indirectness and absolute repetition. They were only used for the problems for which they were generated and hence not comprehensive. For them to be differentiable to a specific pattern, few of them need functions and only a small number of them can withstand constraints. In the case of Meta heuristic optimization methods, advancement in computer capacities, and mathematical applications characterize their high popularity and applications.

Generic Algorithm and Simulated Annealing were some of the by-products of these optimization techniques. Ant Colony, Swarm Particle, Big Bang and Big Crunch technique, Harmony Search, Tabu Search, etc. generated through hybrid applications of these techniques. It would be technically impossible for these types of optimization techniques to be used in many structural applications without the advancement of computer programming and mathematical innovations.

Classical techniques of structural optimization's overview were given by [10]. The ones that were prominent among them with transforming iterations were the linear programming and sequential linear programming. Complex problems are resolved using this method infused into finite element programs. The genetic algorithm concept for resolving structural optimization problems was investigated by [11] and [12] studied large space structures. Shape optimization was researched by [13]. Basic energy deliberations in structures were investigated by [14].

Meta heuristic techniques were investigated by [15] and [16-20]. Simulated annealing (SA) is a mathematical random variable probability relaxation process similar to the method of metal annealing. This method is related to an absolute method of optimization. The idea of energy relates to the structure cost while state transformation relates to transforming to a new set of design variables. SA uses specimens from the probability distribution of the system to randomly produce original formations. [21] and autonomously [22] first promulgated the concept of simulated annealing algorithm.

Simulated annealing is a hypothetically founded, effective, and productive search process suitable to actual constrained optimization which has been effectively adapted to engineering optimization problems. [23] Studied single and multi-objective structural optimization problems using simulated annealing. Simulated annealing was preferred to gradient-based and discrete optimization methods according to their findings.

Several structural optimization tools such as simulated annealing, genetic algorithms, and branch-and-bound were related by [24] to determine the suitability to structural engineering optimization with discrete variables. It was suggested by [25] that a productive means of providing a more effective solution for engineering challenges and reducing the processor time using simulated annealing is to incorporate adequate parallelism options. 


\section{MATERIALS AND METHODS}

The minimization of any function subjected to certain constrained can be accomplished through many procedures i.e., simulated annealing and genetic algorithm. The problem is often presented as Minimum of $\mathrm{f}(\mathrm{x})$ subjected to a set of optimization constraints $\mathrm{g}_{\mathrm{i}}(\mathrm{x})<0$.

Achieving the minimum cost of reinforced concrete rectangular beam is a problem of simulated annealing as other optimization processes. The cost of the R.C. beam production constitutes the objective function to be minimized subject to both flexural and geometric constraints. Thus, the objective function is given as:

$$
f=C_{c}\left[b(d+c)-A_{s}\right]+C_{s}\left[A_{s}\right]+C_{f}[b+2(d+c)]
$$

Let the tensile steel/cross section area $\rho=A_{s t} / b d$.

Thus equation (1) becomes:

$$
f=C_{c}[b(d+c)-\rho b d]+C_{s} \rho b d+C_{f}[b+2(d+c)]
$$

Let the beam width $b$ be $x_{1}$, depth of the beam $d$ be $x_{2}$ and $r$ be $x_{3}$.

where $C_{c}$ is the cost/unit length of concrete, $C_{s}$ is the cost unit/length of steel, $C_{f}$ is the cost/unit area of the formwork.

Substituting those variables into equation (2) yields:

$$
f\left(x_{1}, x_{2}, x_{3}\right)=\left[x_{1}\left(x_{2}+c\right)-x_{1} x_{2} x_{3}\right] C_{c}+x_{1} x_{2} x_{3} C_{s}+\left[x_{1}+2\left(x_{2}+c\right)\right] C_{f}
$$

The design flexural constraint is derived from the Figure 1.

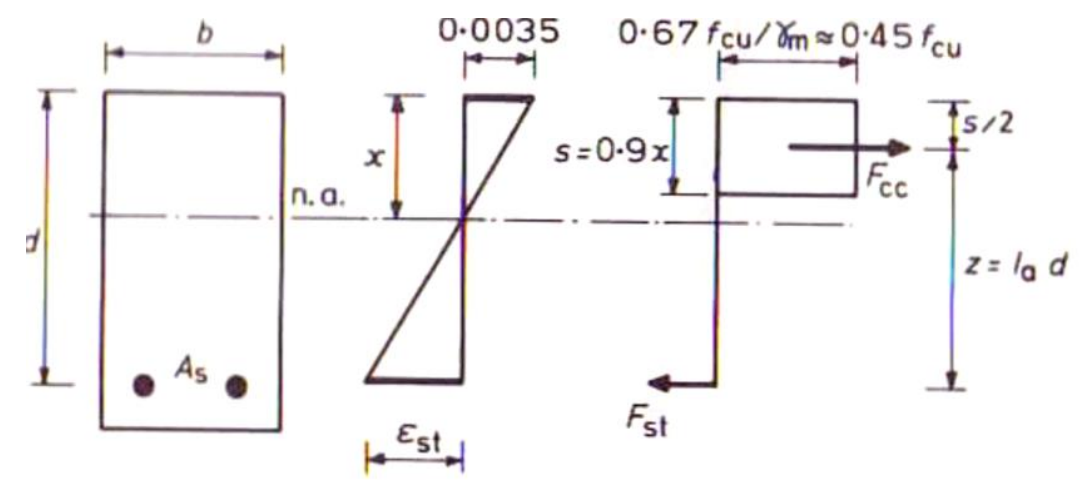

Fig. 1. Section analysis for a singly reinforced rectangular beam [26].

$$
\begin{gathered}
0.45 f_{c u} b s=0.87 f_{y} A_{s} \\
s=\frac{1.9333 \rho d f_{y}}{f_{c u}} \\
z=d-\frac{s}{2}
\end{gathered}
$$

The moment of resistance $M_{r}$ is given as:

$$
\begin{gathered}
M_{r}=C_{c} z \\
M_{r}=0.87 b d^{2} \rho f_{y}\left(1-\frac{0.97 \rho f_{y}}{f_{c u}}\right)
\end{gathered}
$$

The flexural constraint is: 


$$
M_{a}-M_{r} \leq 0
$$

Other constraints are:

$$
\begin{array}{r}
0.0025-\rho \leq 0 \\
\rho-0.04 \leq 0 \\
b \geq 230
\end{array}
$$

The whole process is programmed in Java using all the equations presented overleaf. The simulated annealing procedure is presented in the pseudo-code in Figure 2.

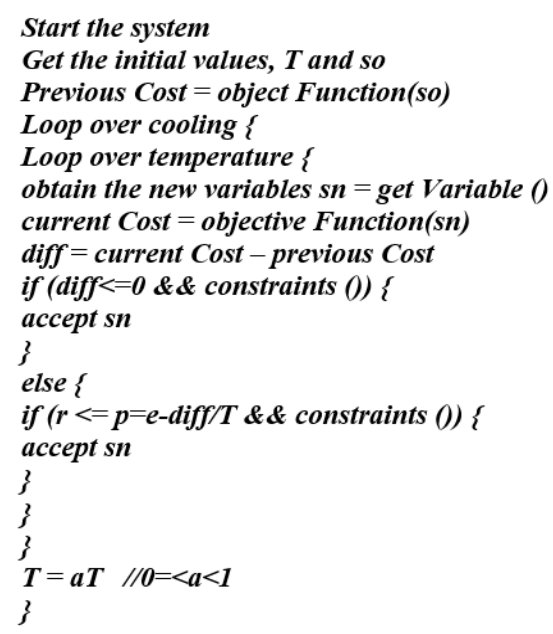

Fig. 2. Pseudo-code for the simulated annealing.

The pseudo-code was developed into a Java program and tested to ascertain its accuracy. The program was then used to generate the parametric data presented in Figures 4 to 7 in the next sections. However, the optimum temperature to adopt in the parametric study is shown in Figure 3 which shows clearly that any temperature between $500^{\circ} \mathrm{C}$ and $600^{\circ} \mathrm{C}$ is the appropriate temperature to adopt.

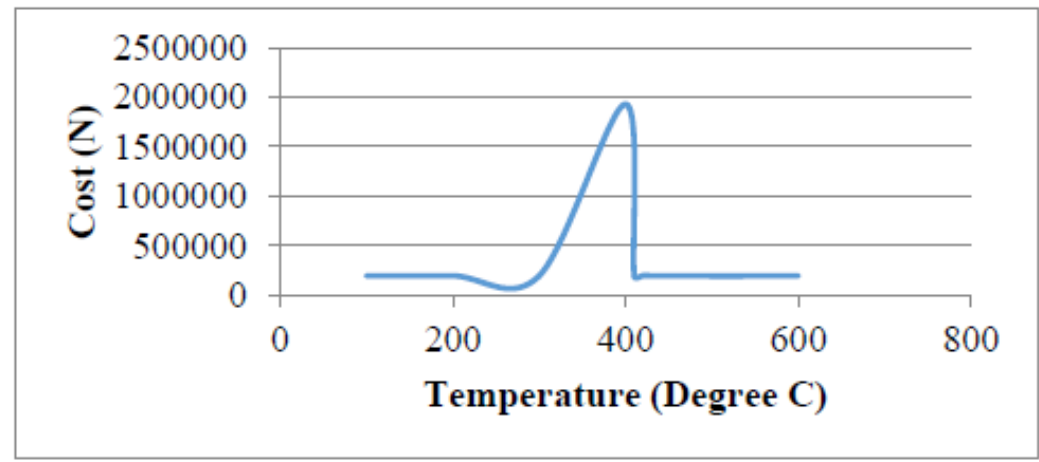

Fig. 3. Variation of temperature with cost.

\section{RESULTS AND DISCUSSION}

The results of the variation of the width, depth, steel ratio, and cost with the moment are presented in this section. Figure 4 is the variation of optimized beamwidth with increasing bending moment. It is evident from the plot that 
the minimum widths are exhibited at various moments such as at 30,50 , and $100 \mathrm{kNm}$. The minimum width of about $230 \mathrm{~mm}$ is exhibited at about $30 \mathrm{kNm}$ moment.

The highest width of about $237 \mathrm{~mm}$ is exhibited at the moment of about $120 \mathrm{kNm}$. Ironically, at the much higher moment of about $160 \mathrm{kNm}$, the width is about $231 \mathrm{~mm}$ far lower than that of $120 \mathrm{kNm}$ moment. This may be as a result of higher depth at $160 \mathrm{kNm}$.

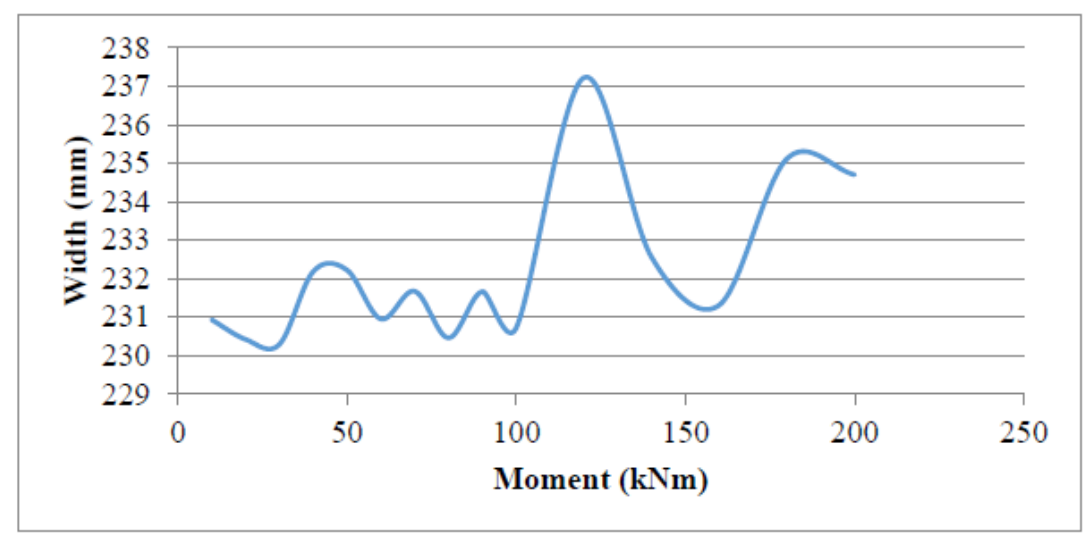

Fig. 4. Optimized beam width at various moments.

Figure 5 is the variation of optimized beam depth with bending moment. It is evident from the plot that the depth remains constant at about $300 \mathrm{~mm}$ between the moment of 10 and about $100 \mathrm{kNm}$ afterward, the depth increases steadily with the moment. The geometrical requirement increases with an increase in the moment.

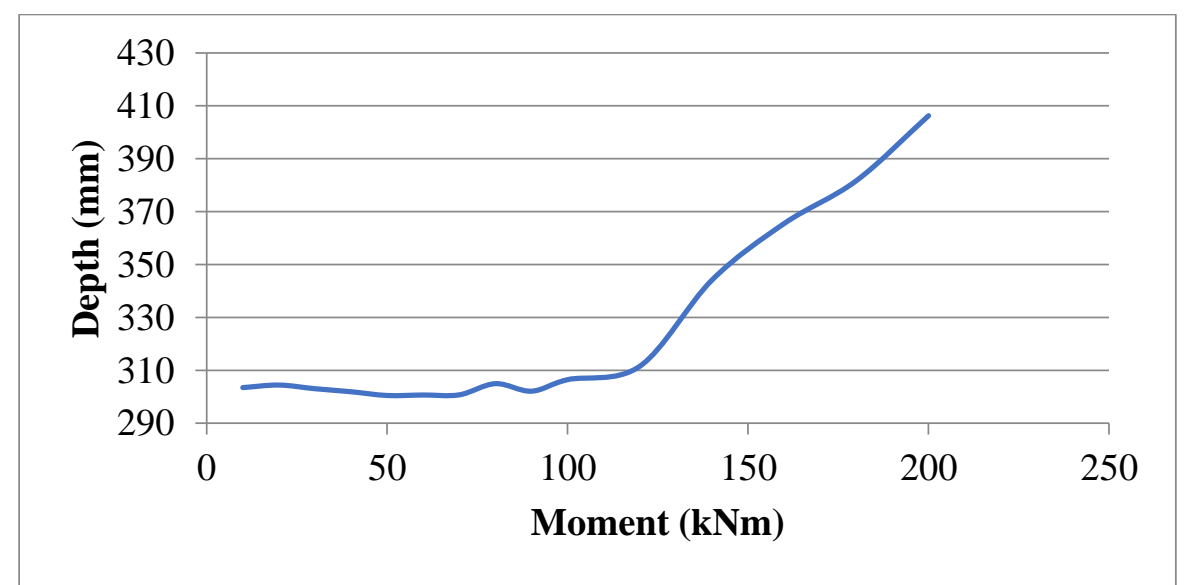

Fig. 5. Optimized beam depth at various moment.

Figure 6 is the plot of the optimized steel ratio variation with the moment. The minimum steel ratios of 0.08 and 0.21 are exhibited at the moment of about 25 and $80 \mathrm{kNm}$ respectively. At about $100 \mathrm{kNm}$ and above the steel ratio is constant at the set maximum of $4 \%$ of the sectional area (Ac).

The pegging of the maximum reinforcement to $4 \%$ Ac leads to a steady increase in depth as shown in Figure 5. This is an indication of the geometric requirement controls the optimized solution.

Figure 7 is the variation of the optimized cost with the moment. The cost remains constant up to the moment of about $90 \mathrm{kNm}$ before a steady increase with the moment. That shows clearly that optimized is invariant with a moment until a certain threshold is passed.

Even though steel requirement varies significantly within the spectrum of the almost constant cost, it is evident that steel cost contribution to the evaluated cost is minimal. Geometry is the main influential component of the overall objective. 


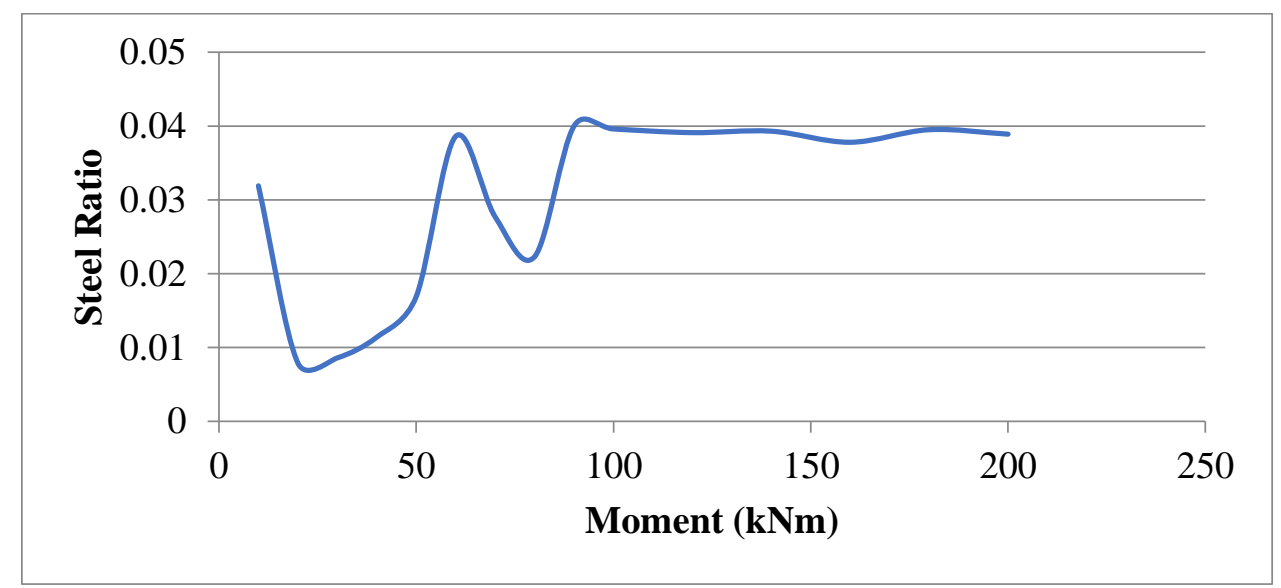

Fig. 6. Optimized steel ratio variation with moment.

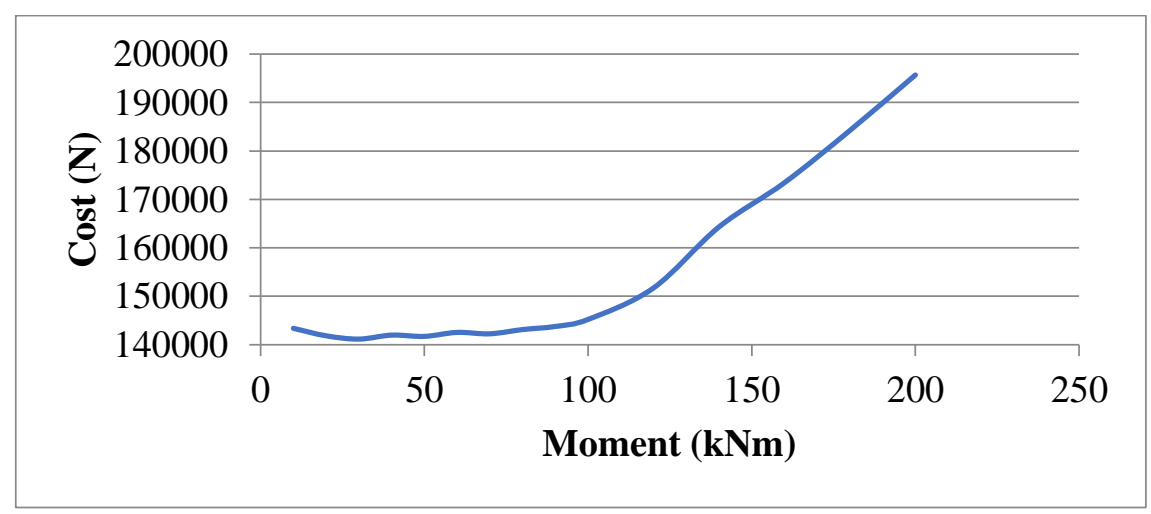

Fig. 7. Optimized cost variation with moment.

\section{CONCLUSION}

It is apparent that for a singly reinforced rectangular beam, the geometry demands govern the cost of construction. Simulated annealing is established to be an effective process of structural cost optimization. The method also proves to be as efficient as other methods of structural optimization such as a genetic algorithm etc. It is observed from the analysis that the minimum widths are exhibited at various moments such as at 30,50 , and $100 \mathrm{kNm}$.

The depth remains constant at around $300 \mathrm{~mm}$ between the moment of 10 and about $100 \mathrm{kNm}$ but increases consistently with respect to the moment afterwards. The geometry of the section also increases proportionally with the moment. Although the specifics of steel requirements vary drastically in the scope of the nearly fixed cost, it is obvious that steel cost impact on the estimated cost is negligible. The overall objective is mainly influenced by the geometry.

\section{REFERENCES}

[1] Quaranta, G., Fiore, A., Marano, G.C., Optimum design of prestressed concrete beams using constrained differential evolution algorithm, Structural and Multidisciplinary Optimization, vol. 49, 2014, p. 441-453.

[2] Scodeggio, A., Quaranta, G., Marano, G.C., Monti, G., Fleischman, R.B., Optimization of force-limiting seismic devices connecting structural subsystems, Computers and Structures,vol. 162, 2016, p.16-27.

[3] Chatterjee, S., Sarkar, S., Hore, S., Dey, N., Ashour, A.S., Balas, V.E., Particle swarm optimization trained neural network for structural failure prediction of multistoried RC buildings, Neural Computation, vol. 28, 2017, p. 2005-2016.

[4] Quaranta, G., Monti, G., Marano, G.C., Parameters identification of Van der Pol-Duffing oscillators via particle swarm optimization and differential evolution, Mechanical Systems and Signal Processing, vol. 24, 2010, p. 20762095. 
[5] Sarma, K.C., Adeli, H., Cost optimization of concrete structures, Journal of Structural Engineering, vol. 124, 1998, p. 570-578.

[6] Sassu, M., Puppio, M.L., Mannari, E., Seismic reinforcement of a RC school structure with strength irregularities throughout external bracing walls, Buildings, vol. 7, no. 58, 2017, p. 1-13.

[7] Puppio, M., Pellegrino, M., Giresini, L., Sassu, M., Effect of material variability and mechanical eccentricity on the seismic vulnerability assessment of reinforced concrete buildings, Buildings, vol. 7, no. 66, 2017.

[8] Hejazi, F., Toloue, I., Jaafar, M.S., Noorzaei, J., Optimization of earthquake energy dissipation system by genetic algorithm, Computer Aided Civil and Infrastructure Engineering, vol. 28, 2013, p.796-810.

[9] Martins, A.M., Simões, L.M., Negrão, J.H., Optimization of concrete cable-stayed bridges under seismic action. Computers and Structures, vol. 222, 2019, p.36-47.

[10] Haftka, R.T., Gürdal, Z., Elements of structural optimization, Ed. Kluwer, 1992.

[11] Frangopol, D.M., Cheng, F.Y., Advances in structural optimization, Ed. ASCE, New York, 1997.

[12] Kamat, M.P., Optimization issues in the design and control of large space structures, Ed. American Society of Civil Engineers, New York, 1985.

[13] Bugeda, G., Oliver, J., A general methodology for structural shape optimization problems using automatic adaptive remeshing, Ed. John Wiley and Sons Ltd, 1993.

[14] Oden, J.T., Mechanics of elastic structures, Ed. McGraw-Hill, 1997.

[15] Hatay, T., Toklu,Y.C., Optimization of trusses using simulated annealing method, 5th International Congress on Advances in Civil Engineering, Istanbul, Turkey, vol. 1, 2002, p. 379-388.

[16] Toklu, Ş.Ç., Nonlinear displacement analysis of trusses using ant colony optimization, Thesis, Bahçeşehir University, Istanbul, 2008.

[17] Toklu, Y.C., Application of optimization techniques to structural analyses: truss example, Structures 2004 Congress, Nashville, Tennessee, USA, 2004, p. 22-26.

[18] Toklu, Y.C., A new technique for nonlinear analysis of trusses, ACE2004, $6^{\text {th }}$ International Congress on Advances in Civil Engineering, Istanbul, Turkey, 2004.

[19] Toklu, Y.C., Nonlinear analysis of trusses through energy minimisation, Computers and Structures, vol. 82, 2004, p.1581-1589.

[20] Toklu, Y.C., Considerations on the design of space structures - active design and inclusion of nonlinear effects, 9th ASCE ASD International Conference- Earth and Space, League City/Houston, Texas, USA, 2004, p.704-710.

[21] Kirkpatrick, S., Gelatt, C.D., Vecchi, M.P., Optimisation by simulated annealing, Science, vol. 20, no. 4598, 1983, p. 671-680.

[22] Cerny, V., Thermodynamical approach to the travelling salesman problem: An efficient simulation algorithm, Journal of Optimization Theory and Applications, vol. 45, 1985, p. 41-51.

[23] Bennage, W.A., Dhingra, A.K., Single and multiobjective structural optimization in discrete-continuous variables using simulated annealing, International Journal for Numerical Methods in Engineering, vol. 38, no.16, 1995, p. 2753-2773.

[24] Manoharan, S., Shanmuganathan, S., A comparison of search mechanisms for structural optimisation, Computers and Structures, vol. 73 no. 1-5, 1999, p .363-372.

[25] Leite, J.P.B., Topping, B.H.V., Parallel simulated annealing for structural optimisation, Computers and Structures, vol. 73, no. 1-5, 1999, p. 545-564.

[26] Mosley, W.H., Bungey, J.H., Reinforced concrete design, $14^{\text {th }}$ Edition Macmillan, 1990. 